\title{
Site-specific prolapse surgery. II. Vaginal paravaginal repair augmented with either synthetic mesh or remodelling xenograft
}

\author{
Richard I. Reid • Kehui Luo
}

Received: 22 April 2009 /Accepted: 27 October 2010 /Published online: 11 January 2011

(C) The Author(s) 2011. This article is published with open access at Springerlink.com

\begin{abstract}
Introduction and hypothesis This study aims to answer the question, "Does tissue augmentation improve the mechanical repair of displacement cystourethrocoele?"

Methods A retrospective cohort study comparing 108 bridging graft vaginal paravaginal repairs (89 tissue-inductive xenografts and 19 polypropylene mesh) to 59 native tissue historical controls was conducted. Main outcome measures were same-site prolapse recurrence and time to failure. Initial reliability was evaluated by chi-squared test, 10-year durability by Kaplan-Meier survival analysis and risk factors by Cox regression.

Results Late recurrence was $17.7 \%$ lower with augmentation (logrank test $\chi^{2}=8.4, p$ value $=0.0038<0.05$, adjusted regression analysis $\chi^{2}=2.94$; $p$ value $=0.0866<0.10$ ), implicating collagen degeneration in repair failure.

Conclusions Rebuilding the pubocervical septum, from arcus to arcus and pubic ramus to pericervical ring, satisfies the mechanical but not the metabolic hernia principles. Bridging grafts simplify technical repair (reducing prolapse persistence from $10.2 \%$ to $4.6 \%$ ), and also rejuvenate adjacent connective tissue (reducing late recurrence from $22.6 \%$ to $4.9 \%$ ).
\end{abstract}

Part I of this article can be found at DOI 10.1007/s00192-010-1347-2.

\section{R. I. Reid}

School of Rural Medicine,

Armidale, Australia

\section{K. Luo}

Statistics Department, Macquarie University,

Sydney, Australia

\section{R. I. Reid ( $\square)$}

Specialist Medical Centre,

Suite \#4, 235 New South Head Rd, Edgecliff,

Sydney, NSW 2027, Australia

e-mail: richard_reid@dbgyn.com
Keywords Connective tissue pathology Cystocoele aetiology $\cdot$ Hernia/therapy $\cdot$ Reconstructive surgical procedures/pelvis/methods · Tissue engineering bioprosthesis · Vaginal paravaginal repair/treatment outcome

\section{Introduction}

Pelvic floor disorders are a cluster of urinary, sexual or defaecation problems that arise mainly out of structural damage or neuromuscular disruption to the pelvic floor, rather than through any malfunction of the specific organs themselves. One in two parous women (versus one in ten men) experiences some type of pelvic floor disorder during her lifetime. At entry examination, $41 \%$ of the participants in the Women's Health Initiative study had clinically significant prolapse [1]. Anterior vaginal wall was the most commonly affected segment. Fifty-five percent of subjects had a dominant single bulge and another $20 \%$ had a cystocoele as part of a diffuse pattern of support failure. This is important because cystocoele repair is relatively unsuccessful. However, pelvic surgeons are seldom confronted with their own operative failures; women tend to suffer in silence, or seek referral elsewhere. Nonetheless, $29 \%$ of the 150,000 insured women at Kaiser Permanente North West in 1995 needed at least one repeat surgery [2]. Applying an epidemiologic "rule of thumb" from the hernia literature, that another $40 \%$ of failures would not have returned [3], overall success rate was perhaps $\sim 60 \%$. Historically, case series reporting on plication-type cystocoele repair claimed success rates around $75-100 \%$. More rigorous examination in recent randomised controlled trials has shown anterior colporrhaphy to be less effective than previously believed. Two recent RCTs report ana- 
tomic success rates of just $57 \%$ at 1 year [4] and $39 \%$ at 2 years [5]. Prevalence of pelvic floor disorders increases in a linear fashion with age [6] but consultations for pelvic floor disorders have a Gaussian distribution [7], suggesting that many women over 60 years lose faith in the treatments offered and hence no longer attend.

Cystocoele repair has been problematic for several reasons [8]. Pelvic anatomy is complex, difficulty increases with time and tissue weakness, and reparative efforts have been confounded by 100 years of mechanically misdirected surgical strategies. In normal women, the pubovisceral muscles compensate pressure-induced stress on the midvaginal fascial supports by narrowing the genital hiatus, while the levator plate acts as a dynamic backstop to dissipate Valsalva forces. Net effect is that the pelvic floor muscles absorb most of the expulsive load on the pelvic organs, and it is very difficult for the body to compensate any muscle damage. Endopelvic fascia is also important, but in a less direct way. Pelvic connective tissue is basically an embryologic mesentery, which tethers the pelvic viscera to the axial skeleton. Its main suspensory role is to stabilise the organs over the posterior levator plate, where the pelvic floor muscles work most effectively. Given that muscle damage sustained at childbirth is not presently reparable, our strategies for re-suspending the sagging pelvic organs depend unduly on connective tissue strength. Unfortunately, endopelvic fascia is not structurally suited to chronic loadbearing, making the task of prolapse repair intrinsically difficult. Any connective tissue weakness would be expected to exacerbate this inherent flaw, potentially undermining even the most skillful traditional repair. Experience accrued by herniologists in averting healing failure due to collagen weakness might therefore have useful lessons for the pelvic reconstructive surgeon.

Retrospective analysis of an 11-year database showed sutured vaginal paravaginal repair (VPVR) to be a genuinely curative treatment for severe displacement cystocele. Whether a $69.5 \%$ success rate from native tissue vaginal VPVR truly justifies the additional surgical effort involved in paravaginal repair instead of anterior colporrhaphy (as a palliative treatment) or mesh-augmented paravaginal repair (as a more robust curative procedure) is debatable. General surgeons have identified connective tissue weakness adjacent to the suture lines as an important factor in failed hernia repair (discussed at length elsewhere) [8]. There is evidence that collagen weakness sometimes develops in longstanding prolapse, raising the question of whether pelvic reparative strategies should also address this phenomenon. We hypothesised that measures to strengthen the central fascia of the anterior vaginal wall trapezoid would improve repair durability, over and above what was attainable by site-specific repair of the causative fascial defects.

\section{Methods}

Study design is a retrospective cohort analysis of augmented versus native tissue VPVRs. The cohorts were generated from a database of 275 consecutive site-specific prolapse repairs over an 11-year period (1997-2007). Data collection was regarded as a quality assurance project, and therefore exempted from Human Research Ethics Committee review. In all, there were 59 native tissue repairs and 108 tissueaugmented VPVRs. The key date with respect to treatment assignment was January 2004, when the first tissue-inductive biomesh (Surgisis ES $^{\circledR}$ : Cook Medical Incorporated, Bloomington, IN) was licensed in Australia. Prior to this date, VPVR was done by re-suture of native tissues using the "three point" technique. After January 2004, sutured VPVR was abandoned in favour of a bridging graft technique. Surgisis ES $^{\circledR}$ was the favoured graft in most privately insured women and some public cases ( 89 women). In the synthetic mesh subgroup, a relatively lightweight monofilament, macroporous polypropylene knit $\left(G_{y n e m e s h}{ }^{\circledR}\right.$ : Ethicon, Somerville, NJ) was used in 15 women and a hernia weight Amid class I knit (Marlex ${ }^{\circledR}$, CR Bard Inc, Murray Hill, NJ) was used in four women. These four Marlex ${ }^{\circledR}$ cases were treated before 2002 (i.e., prior to the availability of prolapsespecific polypropylene meshes). Hernia weight mesh was used to forestall an extreme risk of poor outcome, these four women having failed a total of 16 previous sutured prolapse repairs. Despite differences in mesh weight, we included these four Marlex ${ }^{\circledR}$ cases in the augmentation group. There is no evidence that differences in mesh weight materially impact repair outcome [8]. All four had a successful anatomic outcome, but the mesh had to be removed in two women. Omitting the Marlex ${ }^{\circledR}$ cases would have made our results appear more favourable than they actually were.

Primary measures of outcome were: same site (anterior segment) prolapse recurrence, time to failure and any significant surgical complication. Secondary measures of outcome were different sites (postero-apical segment), anatomic recurrence and persistent or de novo pelvic organ dysfunction. In that data collection began before POPQ staging had become widely established, anatomic outcome was gauged by the Baden Walker "halfway" system. Objective anatomic success was defined as either ideal support (B-W stage 0) or mild laxity (B-W stage 1). Functional success was determined from answers to a symptom inventory, completed at presentation and at yearly follow-up. Mean follow-up time was 55 months (range $=4$ 120 months) for native tissue and 23 months (range $=3$ 44 months) for augmented cases.

Statistical analysis examined short-term reliability and long-term durability of cystocele repair. The reliability with which an effective mechanical repair had been achieved initially was gauged at the 6-month postoperative visit, 
using chi-squared test of independence and logistic regression. Long-term anatomical durability of an initially successful repair was examined with the Kaplan-Meier survival curves and log rank test, then further evaluated using the Cox proportional hazards model.

\section{Results}

Group comparison (using chi-squared test) showed no statistical difference in the distribution of potentially confounding variables including age, body mass index (BMI) $>25 \mathrm{~kg} / \mathrm{m}^{2}, \geq$ stage III descensus, prior or concomitant hysterectomy, prior failed surgery, severe urinary incontinence or suspected collagen weakness ( $p$ values $>0.05$ ), except for multi-compartment repair $\left(\chi^{2}=10.324, p\right.$ value $=$ 0.003 ; Table 1). Given that the primary surgical philosophy was to "leave the entire tract intact" after the index operation, overt or incipient apical support weakness was repaired in 146 subjects (21 by uterosacral ligament culdoplasty and 125 by sacrospinous ligament fixation). Prolapse recurrence in the group needing only cystocele repair did not differ significantly from that when concomitant culdoplasty or sacrospinous ligament fixation was performed [six of $21(71 \%)$ vs five of $21(76 \%)$ vs 17 of 125 $(86 \%) ; \chi^{2}=3.742, \quad p$ value $\left.=0.309>0.05\right]$.

Vaginal paravaginal repair (VPVR) by either technique exhibited genuine curative potential for cystocoele, as evidenced by absolute flattening of the Kaplan-Meier survival curve at 20 months in the augmented group and at 38 months in the native tissue group (Fig. 1). The likelihood of restoring normal anterior compartment anatomy at 6 months was unaffected by use of a bridging graft [103 of $108(95.4 \%)$ vs 53 of $59(89.8 \%) ; \chi^{2}=1.903$, $p$ value $=0.292>0.05]$. However, twelve sutured VPVRs failed over the succeeding 32 months (three at 7-12 months; four at 13-24 months; four at 25-36 months and one at 3748 months), reducing 10 -year success rate to $69.6 \%$. In contrast, there were only five late augmentation failurestwo at 6-12 months and three at 13-24 months (Table 2). Cumulative probability of objective anatomic success was 0.94 at 1 year and 0.91 at 2,3 , and 4 years in the augmented group versus 0.85 at 1 year and $0.78,0.71$ and 0.69 at 2,3 , and 4 years after native tissue repair, respectively. Logrank test confirmed that this divergence of survival analysis curves over time was statistically significant $\left(\chi^{2}=8.4, p\right.$ value $\left.=0.0038<0.05\right)$. Augmented repair also appeared superior by unadjusted regression analysis $\left(\chi^{2}=4.24 ; p=0.0395<0.05\right)$. But adding age, patient domicile and multi-compartment repair outcomes to the Cox proportional hazards model slightly changed the hazards ratio (from 0.430 to 0.465 ), and the difference between groups was only significant at the $10 \%$ level
( $p=0.0866<0.10$; Table 3 ). All potential confounder variables had high $p$ values and wide $95 \%$ confidence intervals that crossed unity by a large margin, implicating the dual effect of small sample size and high censoring as major contributory factors. The impact of selection bias in this study is difficult to establish because of the non-random treatment assignment.

Both surgical techniques relieved bulge discomfort, with augmented VPVR being somewhat better (Table 4a). Seventy-six percent of women either remained or were rendered dry to mechanical provocation following VPVR, with a weak trend in favour of the augmentation group (Table 4b). Thirteen women with persisting stress urinary incontinence opted for bulking injection or mid-urethral sling placement as a follow-up procedure. 'Overactive bladder wet' symptoms were resolved or greatly ameliorated in $56 \%$ of the 109 women who had urge urinary incontinence at presentation. There was a trend in favour of augmented VPVR, falling just short of $p=0.05$ (Table 4c). Finally, pre-existing dyspareunia was resolved in 13 of 21 augmented VPVR and in three of eight native tissue repairs; however, six individuals in the first and two in the second group developed de novo dyspareunia (largely attributable to the use of synthetic mesh). This represented a $28 \%$ decrease in the overall dyspareunia rate (from 29 to 21 complainants).

Anatomic outcome appeared to improve with tighter conformity to the hernia principles (Table 5). Suture-only paravaginal repair was successful in only 41 of 59 (69.5\%) at 10 years. Augmentation with synthetic mesh delivered almost perfect anatomic outcomes, but the polypropylene had to be removed in three of 19 women-reducing ultimate success rate to $84.2 \%$. Best performing biomaterial proved to be Surgisis ${ }^{\circledR}$ ES (Cook Medical Incorporated, Bloomington, IN). Surgisis ${ }^{\circledR}$ ES is an acellular lyophilized xenograft harvested from porcine small intestinal submucosa and fabricated into a strong 4-ply multilaminate. Second-generation biologicals like Surgisis ${ }^{\circledR}$ ES have tissue-inductive properties not found in denatured xenografts [9]. The robust capacity for constructive remodelling yielded anatomic success in 82 of $89(92.1 \%)$ women, and rapid bio-absorption of the implanted xenograft (usually within 3 months) protected against mesh morbidity.

Overall, there were eight $(4.8 \%)$ perioperative surgical complications - three $(5.1 \%)$ occurring in the 59 native tissue group and five (4.6\%) in the 108 augmented repairs. While there was no statistical difference between these small numbers, it is a surgical reality that the use of a bridging graft made the operation of vaginal paravaginal repair quicker and easier to perform. None of these adverse events were unique to the operative technique. Of the dissection-related surgical complications, there were two pelvic hematomas and one transient ureteral obstruction (from swelling of adjacent tissues). There were two (50\%) mesh-related complications 
Table 1 Group comparison of baseline demographics and potentially confounding factors

\begin{tabular}{|c|c|c|c|}
\hline $\begin{array}{l}\text { Baseline demographics and potential } \\
\text { confounders }\end{array}$ & $\begin{array}{l}\text { Augmented vaginal paravaginal } \\
\text { repair }\end{array}$ & $\begin{array}{l}\text { Native tissue vaginal paravaginal } \\
\text { repair }\end{array}$ & $P$ value \\
\hline Mean age & 60.5 years & 61.9 years & 0.309 (n.s.) \\
\hline Multi-compartment prolapse & 101/108 (93.5\%) & $45 / 59(76.3 \%)$ & 0.003 (sig.) \\
\hline Concomitant hysterectomy & 25/108 (23.1\%) & $14 / 59(23.7 \%)$ & 0.932 (n.s.) \\
\hline Prior hysterectomy & 45/108 (41.7\%) & $26 / 59(44.1 \%)$ & 0.764 (n.s.) \\
\hline Prior failed surgery & $41 / 108(38.0 \%)$ & $20 / 59(33.9 \%)$ & 0.602 (n.s.) \\
\hline Suspected collagen weakness & $30 / 108(27.8 \%)$ & $13 / 59(22.0 \%)$ & 0.417 (n.s.) \\
\hline$\geq$ Stage 3 descensus & 79/108 (73.1\%) & $44 / 59(74.6 \%)$ & 0.841 (n.s.) \\
\hline Severe incontinence & $34 / 108(31.5 \%)$ & $23 / 59(39.0 \%)$ & 0.328 (n.s.) \\
\hline $\mathrm{BMI}>25 \mathrm{~kg} / \mathrm{m}^{2}$ & $70 / 108(64.8 \%)$ & $41 / 59(69.5 \%)$ & 0.541 (n.s.) \\
\hline
\end{tabular}

sig. significant, n.s. not significant

in the four women who had Marlex ${ }^{\circledR}$ implants (one vaginal pain lasting 3 years and one vesico-vaginal fistula occurring after 6 years) and one (6.7\%) mesh-related complications among the 15 women who had Gynemesh ${ }^{\circledR}$ implants (a mesh contracture). No biomaterial-related problems were seen in the 89 women having Surgisis ES $^{\circledR}$ implants.

\section{Discussion}

Our null hypothesis was that strengthening the central fascia of the anterior vaginal wall trapezoid would not further

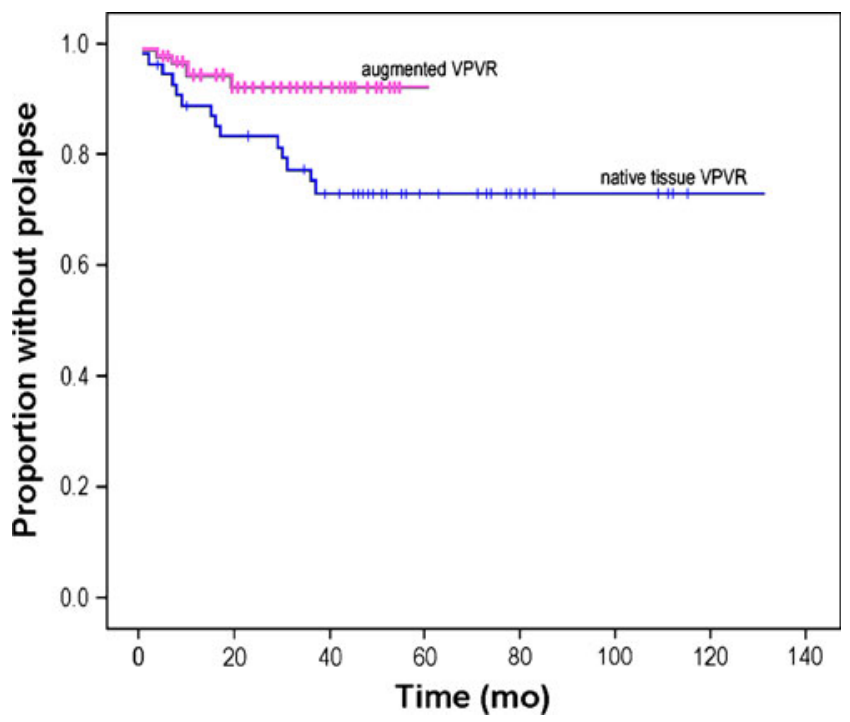

Fig. 1 Ten-year Kaplan-Meier survival analysis data comparing augmented versus native tissue VPVR. The use of any form of augmentation was significantly better than suture-only repair [logrank $\chi^{2}=4.48, p$ value $\left.=0.0343<0.05\right]$. Late failures may have continued for longer in the native tissue group, but the heavy censoring of the augmented group must also be taken into account. Nonetheless, both curves eventually flattened - augmented repair at about 19 months and sutured VPVR at about 38 months. These results suggest that the remaining women had obtained a durable cystocoele repair improve repair durability, over and above what was attainable by re-suture of the causative fascial avulsions. Study results refute this null hypothesis. Use of any form of augmentation significantly outperformed native tissue VPVR, as shown in Fig. $1\left[\chi^{2}=8.4, p\right.$ value $=0.0038<$ 0.05]. Similar results from augmented VPVR have been published elsewhere. Simsiman et al. [10] reported a 78\% 2year success with cross-linked porcine dermis $\left(\right.$ Pelvicol $^{\circledR}:$ CR Bard, Murray Hill, NJ) and Clemons [11] reported a 59\% 4year success with cadaveric human dermis (Alloderm ${ }^{\circledR}$ : Boston Scientific, Natick, MA), a second-generation graft.

The use of implanted materials to re-enforce sagging pelvic support is intuitively logical. Biomaterials (particularly trocar-driven mesh kits) are being used with increasing frequency - despite a paucity of long-term supportive data and the growing safety concerns reported in several systematic reviews [12-15]. The main strength of our study is that we measured the impact of tissue augmentation materials on site-specific native tissue repair over an adequate observation period (5 years). Another strong point is that this study evaluated tissue-inductive xenografts as opposed to the now obsolete first-generation biological implants. Given that minimally altered and chemically adulterated xenografts evoke completely different host immune responses, it is erroneous to combine these two products into a single classification category [9]. This information is well-known to biomaterials scientists, but poorly reported in the medical literature. Like all retrospective investigations, this article has limitations. By the middle of the study period, the first author had become dissatisfied with the "return on effort" from native tissue VPVR. At about this time, two new augmentation materials gained regulatory approval in Australia-Gynemesh ${ }^{\circledR}$ (a flexible light weight synthetic mesh, better suited to prolapse repair) and Surgisis ${ }^{\circledR}$ ES (a tissue-inductive xenograft). In January 2004, surgical technique was therefore changed from sutured repair to a bridging graft 
Table 2 Time to failure in the 28 unsuccessful repairs

\begin{tabular}{|c|c|c|c|c|c|c|c|c|}
\hline \multirow[t]{2}{*}{ Procedure } & \multicolumn{6}{|c|}{ Failure pattern } & \multirow{2}{*}{$\begin{array}{l}\text { Total } \\
\text { failures }\end{array}$} & \multirow{2}{*}{$\begin{array}{l}\text { Number in } \\
\text { group }\end{array}$} \\
\hline & $\leq 6$ months & $\begin{array}{l}6-12 \\
\text { months }\end{array}$ & $\begin{array}{l}\text { 13-24 } \\
\text { months }\end{array}$ & $\begin{array}{l}25-36 \\
\text { months }\end{array}$ & $\begin{array}{l}37-48 \\
\text { months }\end{array}$ & $\geq 48$ months & & \\
\hline \multicolumn{9}{|l|}{ Native tissue group } \\
\hline Native tissue VPVR & 6 & 3 & 4 & 4 & 1 & 0 & 18 & 59 \\
\hline \multicolumn{9}{|l|}{ Augmented group } \\
\hline $\begin{array}{l}\text { Gynemesh }^{\circledR} \text { or Marlex } \\
\text { augmentation }\end{array}$ & $3^{\mathrm{a}}$ & 0 & 0 & 0 & 0 & 0 & 3 & 19 \\
\hline Surgisis $^{(1)}$ augmentation & 2 & 2 & 3 & 0 & 0 & 0 & 7 & 89 \\
\hline Combined augmentation group & 5 & 2 & 3 & 0 & 0 & 0 & 10 & 108 \\
\hline Total & 11 & 5 & 7 & 4 & 1 & 0 & 28 & 167 \\
\hline
\end{tabular}

${ }^{a}$ Mesh was removed from three cases (one for chronic pain, one for contracture, one for vesico-vaginal fistula). Each of these cases was counted here as a 'technical failure' rather than as a 'technical success with an accompanying complication'

technique. However, Surgisis ${ }^{\circledR}$ ES was more expensive than Gynemesh $^{\circledR}$, meaning that choice of mesh was sometimes influenced by patient insurance status. It has been learned in hernia surgery that mesh weight, material stiffness and weave/knit construction must suit the tissue resilience and the degree of movement expected at the graft-host interface. Medium-weight macroporous monofilament polypropylene meshes have worked well in groin hernia repair; but when implanted into the more mobile tissues of a ventral hernia, their torsional rigidity can cause bothersome abdominal wall stiffness [8]. Given that Marlex and Gynemesh are both polypropylene meshes of similar construction (i.e., macroporous monofilament knits), the four women implanted with a hernia weight mesh before
2002 were analysed as a single "synthetic mesh" group. Studies to date have not demonstrated that a reduction in mesh weight delivers lower morbidity [9]. This decision was taken because their omission would have spuriously elevated the relative success of bridging graft VPVR, from 98 of $108(90.7 \%)$ to 96 of $104(92.3 \%)$, as well as omitting the worst of our surgical complications (a mesh-induced vesico-vaginal fistula).

Breaking the stubborn cycle of prolapse recurrence will require an improved understanding of the precise mechanism(s) of failure. Was the site-specific repair unable to secure a sound repair of the existing mechanical defects, or did an initially successful operation subsequently break down due to biochemical weakness in the pelvic connective

Table 3 Cox regression analyses of long-term outcome before (A) and after (B) adjusting for the possible confounders

Analysis of maximum likelihood estimates

\begin{tabular}{|c|c|c|c|c|c|c|c|}
\hline Variable & $\begin{array}{l}\text { Parameter } \\
\text { estimate }\end{array}$ & $\begin{array}{l}\text { Standard } \\
\text { error }\end{array}$ & $\begin{array}{l}\text { Wald chi- } \\
\text { squared }\end{array}$ & $P$ value & $\begin{array}{l}\text { Hazard } \\
\text { ratio }\end{array}$ & \multicolumn{2}{|c|}{$\begin{array}{l}95 \% \text { hazard } \\
\text { range ratio }\end{array}$} \\
\hline \multicolumn{8}{|c|}{ Cox regression: before adjusting for multisegment prolapse } \\
\hline $\begin{array}{l}\text { Survival difference between augmented \& native } \\
\text { tissue VPVR }\end{array}$ & -0.8429 & 0.4093 & 4.242 & $0.0395^{\mathrm{a}}$ & 0.430 & 0.193 & 0.960 \\
\hline \multicolumn{8}{|c|}{ Cox regression: after adjusting for patient age, domicile and multi-compartment repair } \\
\hline Augmented versus native tissue VPVR & -0.7651 & 0.4465 & 2.9363 & $0.0866^{\mathrm{b}}$ & 0.465 & 0.194 & 1.116 \\
\hline Comparing $45-65$ year with $<45$ years age group & 0.3638 & 0.5965 & 0.3721 & 0.542 & 1.439 & 0.447 & 4.632 \\
\hline Comparing $>65$ year with $<45$ years age group & 0.2379 & 0.6053 & 0.1545 & 0.694 & 1.269 & 0.387 & 4.155 \\
\hline Sydney distant domicile vs Sydney local & -0.5881 & 0.6562 & 0.8030 & 0.370 & 0.555 & 0.153 & 2.010 \\
\hline Rural domicile vs Sydney local & -0.1614 & 0.4624 & 0.1219 & 0.727 & 0.851 & 0.344 & 2.106 \\
\hline Rural domicile vs Sydney distant & -0.7051 & 0.7734 & 0.8312 & 0.362 & 0.494 & 0.109 & 2.250 \\
\hline Multi-compartment relapse vs single site & -0.3888 & 0.499 & 0.6062 & 0.436 & 1.475 & 0.554 & 3.925 \\
\hline
\end{tabular}

${ }^{a}$ Significance level of $5 \%$ was used here

${ }^{\mathrm{b}}$ Significance weakened to the $10 \%$ significance level because of small sample size and heavy censoring in years 3,4 and 5 
Table 4 Effect of surgical repair on bulge, stress urinary incontinence and overactive bladder wet symptoms
${ }^{a}$ Twenty-three of the 167 women did not complain of bulge discomfort, reducing subject number to 144

${ }^{\mathrm{b}}$ Fifty-eight of the 167 women did not complain of bulge discomfort, reducing subject number to 109

\begin{tabular}{lll}
\hline Surgical technique & \multicolumn{2}{l}{ Relevant symptom } \\
\cline { 2 - 3 } & Resolved & Failed \\
\hline
\end{tabular}

Symptom control in the 144 women with bulge discomfort $\left(\chi^{2}=5.43 ; p\right.$ value $\left.=0.02<0.05\right)$

$\begin{array}{lcrr}\text { Augmented VPVR } & 86(93.5 \%) & 6 & 92 \\ \text { Native tissue VPVR } & 42(80.8 \%) & 10 & 52 \\ \text { Total } & 128 & 16 & 144^{\mathrm{a}}\end{array}$

Ultimate stress urinary incontinence status within the entire sample $\left(\chi^{2}=2.15 ; p\right.$ value $\left.=0.14>0.05\right)$ $\begin{array}{llll}\text { Augmented VPVR } & 86(79.6 \%) & 22 & 108\end{array}$ $\begin{array}{llll}\text { Native tissue VPVR } & 41(69.5 \%) & 18 & 59\end{array}$

Total $127 \quad 40 \quad 167$

Ultimate symptom control in 109 women with overactive bladder wet $\left(\chi^{2}=3.68 ; p\right.$ value $\left.=0.06>0.05\right)$

$\begin{array}{lccr}\text { Augmented VPVR } & 45(62.5 \%) & 27 & 72 \\ \text { Native tissue VPVR } & 16(43.2 \%) & 21 & 37 \\ \text { Total } & 61 & 48 & 109^{\mathrm{b}}\end{array}$

tissues? Looking at 6-month follow-up (a reasonable surrogate for persistence, as opposed to recurrence) [9, $16]$, initial failure rate was comparable in the two groups [103 of $108(95.4 \%)$ vs 53 of $59(89.8 \%) ; \chi^{2}=1.903, p$ value $=0.292>0.05]$. This observation suggests that both sutured and bridging graft repair were effective methods for overcoming the perennial technical difficulty of locating and mobilising the torn fascial edges. Thereafter, there were five additional failures in the augmented group and 12 in the native tissue group. Delayed failures are a reasonable surrogate for recurrence, as opposed to persistence. That late recurrence was $17.7 \%$ lower in the augmented group [five of $103(4.9 \%)$ versus 12 of $53(22.6 \%)$; logrank test $\chi^{2}=8.4, p$ value $=0.0038<0.05$, unadjusted regression analysis $\chi^{2}=4.24 ; p$ value $=0.0395<0.05$ and adjusted regression analysis $\chi^{2}=2.94 ; p$ value $\left.=0.0866<0.10\right]$ suggests that deterioration in collagen quality within the chronically prolapsed bladder hammocks may be a second important factor in repair failure (Fig. 1). Obtaining an ideal outcome would appear to depend upon correcting both failure mechanisms. This situation is not dissimilar to the problems that general surgeons face with hernia repair.

Hernia is the protrusion of an internal organ (usually small intestine) through a weakness in the abdominal wall. Formation reflects both a mechanical and a metabolic event $[8,16]$. The mechanical event can be a congenital weakness at the internal ring or a traumatic/post-incisional break in the transversalis fascia. Any protruding tongue of peritoneum generally remains subclinical for years; however, progression to symptomatic hernia becomes likely if abdominal wall muscle strength can no longer contain the forces generated during Valsalva straining or at loading of the torso during heavy exertion. Hernia formation is also favoured by any metabolic compromise of the adjacent connective tissue quality-either genetic [8] or acquired
[17]. Somewhat analogous to hernia, cystocoele is a protrusion of the vesical neck and/or bladder base through a site-specific tear in the fascial envelope of the vagina. Progression from subclinical support damage to symptomatic prolapse takes decades, and is largely driven by the operation of diverse secondary events [8].

Over the course of two centuries, general surgeons have developed a set of operative rules to minimise the contribution of mechanical factors to failed hernia repair (Table 4). The cardinal rule was to repair all site-specific fascial defects, sewing identical tissue within the same layer, using interrupted stitches of permanent suture, without undue suture line tension in any direction. It was also traditional to re-secure the abdominal connective tissues to the axial skeleton by sewing the conjoint tendon to the inguinal ligament. These manoeuvres were broadly successful, but excessive wound tension sometimes impeded healing. Some 25 years ago, surgeons turned to mesh implants as the best way of reducing wound tension and postoperative pain [18]. Such a strategy also made repair of the mechanical defect technically easier and serendipitously reinforced any weakness in the adjacent connective tissues. The key question is whether gynaecologists should adopt these surgical rules, at least at a theoretic level [8]. Results from this study appear to support that contention. Success rates for prolapse repair improved with increasing adherence to the hernia principles. Anterior colporrhaphy meets none of these rules, and is predictably inferior [4, 5]. Native tissue VPVR satisfies the criterion of being a site-specific technique, analogous to a Bassini or Shouldice hernia repair. However, all sutured repairs increase wound tension, and any adjacent collagen weakness remains unresolved. Bridging graft repair is exactly analogous to modern prosthetic hernioplasty; it is completely tension-free and carries the added advantage of simplifying the operative 


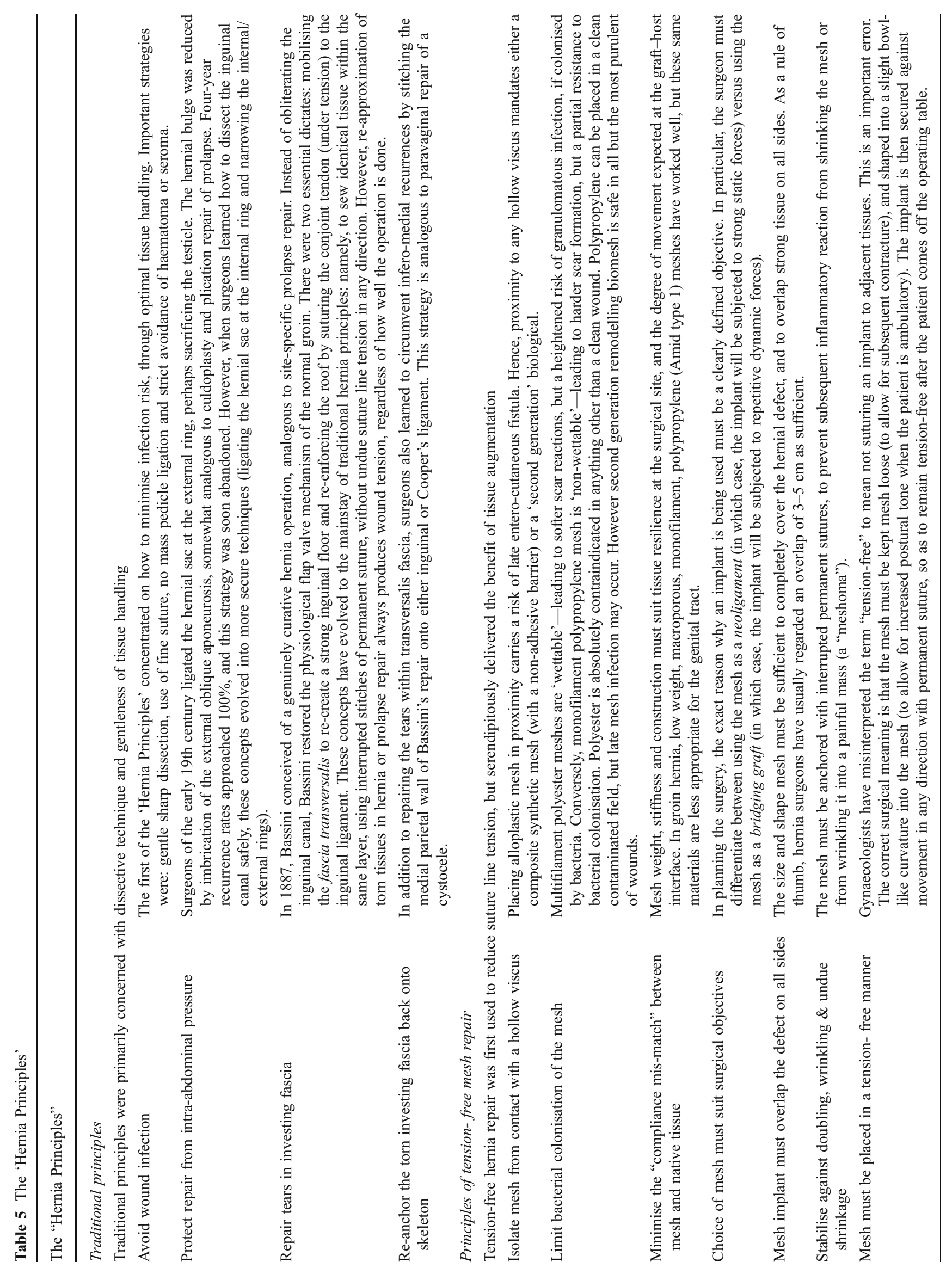


dissection. Results improved with any form of augmentation. All 19 women in the synthetic mesh group had successful anatomic outcomes, reflecting the tension-free attributes and almost indestructible nature of synthetic implants. However, severe mesh morbidity necessitated removal of polypropylene prostheses in three womenreducing ultimate surgical success to $84.2 \%$. Use of Surgisis ${ }^{\circledR}$ ES, a resorbable tissue-inductive xenograft, delivered the best results (92.1\% 5-year anatomic success).

From a research perspective, pelvic reconstructive surgeons do not appear to have grasped some profound differences between the various biomaterials available for prolapse repair. In essence, surgical implants are designed to re-attach an avulsed structure to the body wall by attracting the ingrowth of soft tissue. When considering tissue augmentation, it is intuitive to select an inert permanent material, such as synthetic mesh (e.g., polypropylene and polyester). However, such prostheses always evoke an acute foreign body inflammatory reaction [19]. Subsequent healing response is shaped by two main factors: pore size/accessibility and device motion at the implantation site $[20,21]$. Placing macroporous monofilament (Amid Type I) mesh within immobile tissues generally results in strong vascular and connective tissue ingrowth ("incorporation") [22]. However, poor fixation of an implant can lead instead to excessive shearing stress against host tissue, resulting in micro-bursa formation and poor fixation [21]. Biomaterials scientists in the early 1990s deliberately tanned various cadaveric and animal tissues with glutaraldehyde or hexamethylene diisocyanate to delay or permanently retard collagen turnover [23]. But "leatherizing" these biological materials failed to produce the "natural" scaffolds that manufacturers sought [8]. Clinical outcomes were paradoxical. Graft-to-tissue bonding is relatively weak, analogous to healing around a microporous or multifilament (Amid Type II or III) synthetic mesh. Moreover, there is a potential for subsequent graft autolysis, leading to automatic support failure. FitzGerald et al. [24] reported the failure of 45 of $67(87 \%)$ Tutoplast ${ }^{18}$ sacrocolpopexies and 14 of $35(52 \%)$ Tutoplast $^{\circledR}$ slings. Of 16 cases that came to abdominal re-exploration, 15 women had absent or inadequate graft material. Gandhi et al. [25] found that an adjunct patch graft of Tutoplast ${ }^{\circledR}$ did not reduce the risk of recurrent Stage II cystocoele. Similarly, in a prospective series of rectocele repair, Altman et al. [26] had a 41\% 3-year failure rate due to autolysis of the implanted Pelvicol ${ }^{\mathbb{B}}$ bridging graft. In contrast, preparing an acellular xenograft in a way that preserves both the essential matrix molecules and a virtually intact protein scaffold will evoke a 'graft acceptance' response (modulated by $\mathrm{Th}_{2}$ lymphocytes and tissue-inductive $\mathrm{M}_{2}$ macrophages) $[9,27,28] . M_{2}$ macrophage infiltration leads to constructive remodelling, rather than the familiar 'graft rejection' reaction (modulated by $\mathrm{Th}_{1}$ lymphocytes and phagocytic $\mathrm{M}_{1}$ macrophages) that inevitably accompanies implantation of alloplastic mesh or denatured collagen. Tissue-inductive implants are engineered to repopulate with host fibroblasts and angioblasts within 2-3 weeks, then remodel into a strong and self-renewable repair within 3-5 months. Hence, programmed resorption of a second-generation biological does not result in repair failure. Rather, this rapid resorption is the key reason why Surgisis ${ }^{\circledR}$ ES evokes a constructive remodelling $\mathrm{M}_{2}$ macrophage response. A slower resorption rate would taint the wound with degenerating biomaterial, thus potentially deviating healing towards the phagocytic $\mathrm{M}_{1}$ macrophage response that produces chronic inflammation and late scar formation around synthetic mesh implants $[29,30]$. When implanting a bioactive graft, tissue quality of the repair will depend on the cell source, the growth modulating signals within the graft, the mechanical stresses to which the healing wound is subject and host androgen status [9].

\section{Conclusions}

Prolapse begins with intrapartum avulsion of the suspensory visceral mesenteries from their skeletal anchor points, then evolves to symptomatic descensus as host tissues weaken over time. Durable repair appears to demand two things: that the true site of support failure (i.e., the specific fascial tears, not the secondary central bulges) be repaired without tension and that degenerative tissue bordering the site of the original fascial tear be rejuvenated with a tissue augmentation material, appropriate to that implantation site. Traditional anterior colporrhaphy addresses neither of these surgical essentials. The fundamental objective of VPVR is to rebuild the pubocervical septum from arcus to arcus and from pubic ramus to pericervical ring. Suture-only techniques satisfy the mechanical dictates of the hernia principles, but not the metabolic ones. Conversely, use of an appropriate bridging graft perhaps simplified the technical task of VPVR and serendipitously rejuvenated adjacent connective tissue (reducing late recurrence from $22.6 \%$ to $4.9 \%$ ). It is intuitive to choose an inert permanent material, such as synthetic mesh or a denatured biological. Such prostheses always attract phagocytic $\mathrm{M}_{1}$ macrophages, resulting in cicatrization. Conversely, tissue engineering principles dictate that preserving normal collagen structure and functioning matrix molecules within an absorbable xenograft will attract $\mathrm{M}_{2}$ macrophages, with constructive remodelling as the default healing response. This explains how a temporary bridging graft can transform into a permanent aponeurotic layer of host tissue, without the potential for mesh pain or erosion. Thus, the $21.2 \%$ improvement in 5-year durability attending xenograftaugmented cystocoele repair is of considerable importance- 
especially since use of biomaterials made the operation quicker and more readily standardised than VPVRs done with native tissue. Prospective study is warranted.

Acknowledgements Hui You helped to set up the Excel database, entered all of the study data and assisted in preliminary data exploration.

\section{Conflicts of interests None.}

Open Access This article is distributed under the terms of the Creative Commons Attribution Noncommercial License which permits any noncommercial use, distribution, and reproduction in any medium, provided the original author(s) and source are credited.

\section{References}

1. Hendrix SL, Clark A, Nygaard I, Aragaki A, Barnabei V, McTiernan A (2002) Pelvic organ prolapse in the women's health initiative: gravity and gravidity. Am J Obstet Gynecol 186:1160-1166

2. Olsen AL, Smith VJ, Bergstrom JO, Colling JC, Clark AL (1997) Epidemiology of surgically managed pelvic organ prolapse and urinary incontinence. Obstet Gynecol 89:501506

3. Kald A, Fridsten S, Nordin P, Nilsson E (2002) Outcome of repair of bilateral groin hernias: a prospective evaluation of 1,487 patients. Eur J Surg 168:150-153

4. Sand PK, Koduri S, Lobel RW, Winkler HA, Tomezsko J, Culligan PJ, Goldberg R (2004) Prospective randomized trial of polyglactin 910 mesh to prevent recurrence of cystoceles and rectoceles. Am J Obstet Gynecol 184:1357-1362

5. Weber AM, Walters MD, Piedmonte MR, Ballard LA (2001) Anterior colporrhaphy: a randomized trial of three surgical techniques. Am J Obstet Gynecol 185:1299-1304

6. Swift S (2005) Pelvic organ prolapse: is it time to define it? Int Urogynecol J 16:425-427

7. Brown JS, Waetjen LE, Subak LL, Thom DH, Van den ES, Vittinghoff E (2002) Pelvic organ prolapse surgery in the United States, 1997. Am J Obstet Gynecol 186:712-716

8. Reid RI. (2011) Hernia principles: what general surgeons can teach us about prolapse repair? In: Von Theobald P, Zimmerman CW, Davila W (eds). Vaginal Prolapse Surgery: New Techniques. Springer-Verlag, Guildford (in press)

9. Reid RI (2011) A comparative analysis of biomaterials currently used in pelvic reconstructive surgery. In: Vaginal Prolapse Surgery: New Techniques. Von Theobald P, Zimmerman CW, Davila W (eds). Springer-Verlag, Guildford (in press)

10. Simsiman AJ, Luber KM, Menefee SA (2006) Vaginal paravaginal repair with porcine dermal reinforcement: correction of advanced anterior vaginal prolapse. Am J Obstet Gynecol 195:1832-1836

11. Clemons JL, Myers DL, Aguilar VC, Arya LA (2003) Vaginal paravaginal repair with an AlloDerm graft. Am J Obstet Gynecol 189:1612-1618
12. Jia X, Glazener C, Mowatt G, MacLennan G, Bain C, Fraser C, Burr J (2008) Efficacy and safety of using mesh or grafts in surgery for anterior and/or posterior vaginal wall prolapse: systematic review and meta-analysis. BJOG 115:1350-1361

13. Feiner B, Jelovsek JE, Maher C (2009) Efficacy and safety of transvaginal mesh kits in the treatment of prolapse of the vaginal apex: a systematic review. BJOG 116:15-24

14. Diwadkar GB, Barber MD, Feiner B, Maher C, Jelovsek JE (2009) Complication and reoperation rates after apical vaginal prolapse surgical repair: a systematic review. Obstet Gynecol 113:367-373

15. Foon R, Toozs-Hobson P, Latthe P (2008) Adjuvant materials in anterior vaginal wall prolapse surgery: a systematic review of effectiveness and complications. Int Urogynecol J 19:1697-1706

16. Franz MG (2006) The biology of hernias and the abdominal wall. Hernia 10:462-471

17. Klinge U, Binnebosel M, Mertens PR (2006) Are collagens the culprits in the development of incisional and inguinal hernia disease? Hernia 10:472-477

18. Amid PK (2003) The Lichtenstein repair in 2002: an overview of causes of recurrence after Lichtenstein tension-free hernioplasty. Hernia 7:13-16

19. Klinge U, Klosterhalfen B, Muller M, Schumpelick V (1999) Foreign body reaction to meshes used for the repair of abdominal wall hernias. Eur J Surg 165:665-673

20. Bellon JM, Contreras LA, Bujan J, Palomares D, Carrera-San Martin A (1998) Tissue response to polypropylene meshes used in the repair of abdominal wall defects. Biomaterials 19:669-675

21. Bobyn JD, MacGregor DC (1982) Effect of pore size on the peel strength of attachment of fibrous tissue to porous-surfaced implants. J Biomed Mater Res 16:571-584

22. Trabuco EC, Klingele CJ, Gebhart JB (2007) Xenograft use in reconstructive pelvic surgery: a review of the literature. Int Urogynecol J 18:555-563

23. Badylak SF (2004) Xenogeneic extracellular matrix as a scaffold for tissue reconstruction. Transpl Immunol 12:367-377

24. FitzGerald MP, Edwards SR, Fenner D (2004) Medium-term follow-up on use of freeze-dried, irradiated donor fascia for sacrocolpopexy and sling procedures. Int Urogynecol J 15:238-242

25. Gandhi S, Goldberg RP, Kwon C, Koduri S, Beaumont JL, Abramov Y, Sand PK (2005) A prospective randomized trial using solvent dehydrated fascia lata for the prevention of recurrent anterior vaginal wall prolapse. Am J Obstet Gynecol 192:1649-1654

26. Altman D, Zetterstrom J, Mellgren A, Gustafsson C, Anzen B, Lopez A (2006) A three-year prospective assessment of rectocele repair using porcine xenograft. Obstet Gynecol 107:59-65

27. Valentin JE, Badylak JS, McCabe GP, Badylak SF (2006) Extracellular matrix bioscaffolds for orthopaedic applications. A comparative histologic study. J Bone Joint Surg Am 88:2673-2686

28. Badylak SF, Valentin JE, Ravindra AK, McCabe GP, StewartAkers AM (2008) Macrophage phenotype as a determinant of biologic scaffold remodeling. Tissue Eng A 14:1835-1842

29. Abdel-Fattah M, Ramsay I (2008) Retrospective multicentre study of the new minimally invasive mesh repair devices for pelvic organ prolapse. BJOG 115:22-30

30. Milani R, Salvatore S, Soligo M, Pifarotti P, Meschia M, Cortese M (2005) Functional and anatomical outcome of anterior and posterior vaginal prolapse repair with prolene mesh. BJOG 112:107-111 